Tingkat kreativitas guru untuk mengatasi keterbatasan sarana prasarana dalam proses pembelajaran pendidikan jasmani olahraga dan kesehatan di SMP se-Kecamatan Matesih Kabupaten Karanganyar

\title{
The level of creativity of teachers to overcome the limitations of infrastructure in the learning process of physical education sports and health in Junior High School in Matesih District Karanganyar Regency
}

\author{
Angga Novtianto $\mathrm{H}^{1}$, Waluyo ${ }^{2}$ dan Singgih Hendarto ${ }^{3}$ \\ ${ }^{1}$ Program Studi Pendidikan Jasmani Olahraga dan Kesehatan Fakultas Keolahragaan Universitas Sebelas Maret Jl.Menteri \\ Supeno No.16 Manahan-Surakarta, Jawa Tengah, 57139, Indonesia \\ ${ }^{2}$ Fakultas Keolahragaan Universitas Sebelas Maret Jl.Menteri Supeno No.16 Manahan-Surakarta, Jawa Tengah, 57139, \\ Indonesia \\ ${ }^{3}$ Fakultas Keolahragaan Universitas Sebelas Maret Jl.Menteri Supeno No.16 Manahan-Surakarta, Jawa Tengah, 57139, \\ Indonesia
}

\begin{abstract}
Abstrak
Tujuan penelitian ini adalah untuk mengetahui besarnya tingkat kreativitas guru untuk mengatasi keterbatasan sarana prasarana dalam proses pembelajaran Pendidikan Jasmani, Olahraga dan Kesehatan di SMP se-Kecamatan Matesih, Kabupaten Karanganyar. Penelitian ini merupakan penelitian deskriptif. Penelitian deskrptif adalah penelitian yang dilakukan untuk mengetahui nilai variabel mandiri, baik satu variabel atau lebih tanpa membuat perbandingan, atau menghubungkan dengan variabel lain yang diteliti dan dianalisis sehingga menghasilkan kesimpulan. Subjek penelitian ini adalah guru PJOK se-Kecamatan Matesih, Kabupaten Karanganyar yang berjumlah 10 orang. Teknik pengumpulan data yaitu dengan angket pernyataan. Analisis data menggunakan statistik deskriptif. Hasil penelitian menunjukkan bahwa besarnya tingkat kreativitas guru untuk mengatasi keterbatasan sarana prasarana dalam proses pembelajaran Pendidikan Jasmani, Olahraga dan Kesehatan di SMP se-Kecamatan Matesih Kabupaten Karanganyar, untuk kategori "sangat tinggi” sebanyak 2 guru Penjasorkes atau sebesar 20\%, kategori "tinggi” sebanyak 1 guru Penjasorkes atau sebesar 10\%, kategori "sedang" sebanyak 3 guru Penjasorkes atau sebesar $30 \%$, kategori "rendah" sebanyak 4 guru Penjasorkes atau sebesar 40\%, dan kategori "sangat rendah" sebanyak 0 guru Penjasorkes atau sebesar $0 \%$.
\end{abstract}

Kata kunci : Keterbatasan Sarpras, Kreativitas Guru, Pembelajaran Penjasorkes.

\section{Abstract}

The purpose of this research is to find out the level of creativity of teachers to overcome the limitations of infrastructure in the learning process of Physical Education, Sports and Health in junior high schools in Matesih Subdistrict, Karanganyar Regency. This research is descriptive research. Deskrptif research is research conducted to find out the value of independent variables, either one or 
more variables without making comparisons, or connecting with other variables that are researched and analyzed so as to produce conclusions. The subject of this study was pjok teachers from Matesih sub-district, Karanganyar regency with 10 people. Data collection techniques are by statement questionnaires. Data analysis using descriptive statistics. The results showed that the level of creativity of teachers to overcome the limitations of infrastructure in the learning process of Physical Education, Sports and Health in junior high schools in Matesih Subdistrict, Karanganyar Regency, for the category of "very high" as many as 2 teachers Penjasorkes or by 20\%, category "high" as much as 1 teacher Penjasorkes or by 10\%, category "medium" as much as 3 teachers Penjasorkes or by 30\%, category "low" as many as 4 teachers Penjasorkes or as much as 4\%, and the category "very low" as much as 0 teachers Penjasorkes or by $0 \%$.

Keywords: Limitations of Sarpras, Creativity of Teachers, Learning Penjasorkes.

\section{PENDAHULUAN}

Kebutuhan sarana dan prasarana dalam pendidikan jasmani olahraga dan kesehatan sangat beragam baik jenis maupun jumlahnya sesuai dengan materi dalam kurikulum yang ada. Keberadaan dan kebutuhan sarana dan prsarana sangat diperlukan bagi guru baik dalam memenuhi jumlahnya maupun pemanfaatannya. Sebagian besar keberadaan sarana dan prasarana di sekolah belum mencukupi untuk dapat digunakan guru dalam mengajar semua materi bagi semua siswanya.

Terbatasnya sarana dan prasarana atau alat, perkakas, dan fasilitas olahraga di sekolah menuntut guru pendidikan jasmani olahraga dan kesehatan (PJOK) harus memiliki banyak kreativitas, agar materi pelajaran tetap dapat disampaikan dan dapat diterima dengan baik oleh siswa. Kreativitas seorang guru pendidikan jasmani olahraga dan kesehatan (PJOK) tergantung pada usaha yang dilakukannya untuk mengatasi masalah di atas. Guru pendidikan jasmani olahraga dan Kesehatan (PJOK) yang berusaha dengan segala kemampuannya untuk mengatasi permasalahan yang ada sehingga masalah-masalah yang adatersebut dapat diatasi, maka guru pendidikan jasmani tersebut harus memilki kreativitas.

Kreativitas guru pendidikan jasmani dapat dilihat dari kemampuan yang dimilikinya. Kemampuan tersebut diantaranya adalah bagaimana guru bisa melakukan perbuatan atau perilaku diluar kebiasaan dalam pembelajaran, akan tetapi perilaku itu tidak menyimpang dari tujuan pembelajaran yang sudah dituliskan dalam Silabus dan RPP sehingga siswa-siswi tidak mudah merasa bosan dan tidak mudah menebak pembelajaran apa yang akan diberikan oleh guru dalam materi pendidikan jasmani, olahraga dan Kesehatan.

Beberapa ciri untuk mengetahui kreativitas dapat diketahui dari ketika guru pendidikan jasmani melihat sebuah masalah yang ada, apakah ia memeperhatikan atau tidak memperhatikan sama sekali. Oleh karena itu timbul keinginan untuk memecahkan masalah yang ada atau tidak dan lain sebagainya. Setelah seorang guru pendidikan jasmani melihat sebuah masalah yang ada ia akan berusaha 
menciptakan atau mencari ide-ide yang ada tersebut. Seorang guru pendidikan jasmani seharusnya terbuka terhadap cara-cara baru yang dianggapnya lebih efektif dan efisien digunakan untuk mengajar, sehingga tujuan dari pembelajaran dapat tercapai secara optimal.

Setelah diketahui bagaimana untuk mengetahui tingkat kreativitas guru dari beberapa ciri-ciri yang sudah disebutkan, lalu disusun sebagai pedoman dalam membuat instrumen. Kemudian instrumen diujikan kepada para sampel hingga didapatkan apakah tingkat kreativitasnya sangat tinggi, tinggi, sedang, rendah, dan sangat rendah.

Guru dapat memodifikasi sarana dan prasarana dengan apa yang ada disekitarnya atau dapat pula menggunakan sarana dan prasarana lain yang fungsinya sama sebagai pengganti sarana dan prasarana yang sebenarnya atau dengan usaha lain yang sesuai dengan materi, tujuan pembelajaran, dan karateristik siswa demi tercapainya tujuan pembelajaran pendidikan jasmani yang diharapkan atau yang lebih baik lagi. Contohnya dengan memodifikasi bola, lapangan, permainannya atau aturannya.

Maka dari itu mendorong penulis untuk melakukan penelitian tentang seberapa tinggi tingkat kreativitas guru 3esehatan3 jasmani, olahraga dan 3esehatan (PJOK) untuk mengatasi keterbatasan sarana dan prasarana di SMP se-Kecamatan Matesih, Kabupaten Karanganyar sebagai upaya untuk mengetahui tingkat kreativitasnya dan peningkatan mutu 3 esehatan 3 melalui 3 esehatan 3 jasmani olahraga dan 3esehatan (PJOK).

\section{METODE}

Desain penelitian ini menggunakan metode penelitian deskriptif kuantitatif. Analisis yang sering digunakan adalah analisis deskriptif yang dituangkan dalam bentuk persentase. Metode pengumpulan data dengan menggunakan angket dan dokumentasi. Subyek penelitian menggunakan seluruh guru pendidikan jasmani olahraga dan kesehatan (PJOK) di SMP/MTs negeri maupun swasta se-Kecamatan Matesih Kabupaten Karanganyar. Instrumen yang digunakan dalam penelitian dengan menggunakan angket pernyataan yang berjumlah 40 butir peryataan, terdiri dari 28 pernyataan positif dan 12 pernyataan negatif. Dari data yang terkumpul kemudian dikonversikan ke dalam tabel kategori rentangan norma penilaian dan dianalisis dengan cara deskriptif persentase untuk mengetahui tingkat kreativitas guru untuk mengatasi keterbatasan sarana dan prasarana dalam proses pembelajaran pendidikan jasmani olahraga dan kesehatan di SMP se-Kecamatan Matesih Kabupaten Karanganyar. 
ISSN: 1979-3103

\section{HASIL DAN PEMBAHASAN}

Secara keseluruhan tingkat tingkat kreativitas guru untuk mengatasi keterbatasan sarana dan prasarana dalam proses pembelajaran pendidikan jasmani olahraga dan kesehatan di SMP seKecamatan Matesih Kabupaten Karanganyar dapat dilihat melalui pemaparan tabel norma penilaian sebagai berikut:

$\begin{array}{cccc}\text { No } & \text { Kategori } & \text { Frekuensi } & \% \\ 1 & \text { Sangat Tinggi } & 2 & 20 \% \\ 2 & \text { Tinggi } & 1 & 10 \% \\ 3 & \text { Sedang } & 3 & 30 \% \\ 4 & \text { Rendah } & 4 & 40 \% \\ 5 & \text { Sangat Rendah } & 0 & 0 \% \\ & \text { Jumlah }= & 10 \text { guru } & 100 \%\end{array}$

Tabel 1. Descriptive statistic

\begin{tabular}{|l|c|c|}
\hline & Total & $\begin{array}{c}\text { Valid N } \\
\text { (listwise) }\end{array}$ \\
\hline $\mathrm{N}$ & 10 & 10 \\
Minimum & 121 & \\
Maximum & 144 & \\
Sum & 1303 & \\
Mean & 130,30 & \\
Std. Deviation & 4,067 & \\
\hline
\end{tabular}

Berdasarkan tabel norma penilaian di atas menunjukkan bahwa tingkat kreativitas guru untuk mengatasi keterbatasan sarana dan prasarana dalam proses pembelajaran pendidikan jasmani olahraga dan kesehatan di SMP se-Kecamatan Matesih Kabupaten Karanganyar berada pada kategori "Sangat Tinggi" sebanyak 2 guru Penjasorkes atau sebesar 20\%, kategori "Tinggi” sebanyak 1 guru Penjasorkes atau sebesar 10\%, kategori "Sedang” sebanyak 3 guru Penjasorkes atau sebesar 30\%, kategori "Rendah" sebanyak 4 guru Penjasorkes atau sebesar 40 \%, dan tidak terdapat guru Penjasorkes atau 0\% yang termasuk kedalam kategori "Sangat Rendah”.

Penelitian ini di lakukan dengan tujuan untuk mengetahui besarnya tingkat kreativitas guru untuk mengatasi keterbatasan sarana prasarana dalam proses pembelajaran Pendidikan Jasmani, 
Olahraga dan Kesehatan di SMP se-Kecamatan Matesih Kabupaten Karanganyar. Melalui survei menggunakan angket yang sudah disediakan opsi pilihan jawabannya, yaitu: Sangat Setuju (SS), Setuju (S), Tidak Setuju (TS), dan Sangat Tidak Setuju (STS) dengan keseluruhan sebanyak 40 butir pernyataan, maka penelitian ini telah dapat diketahui hasilnya.

Faktor-faktor yang mempengaruhi besarnya tingkat kreativitas guru untuk mengatasi keterbatasan sarana prasarana dalam proses pembelajaran Pendidikan Jasmani, Olahraga dan Kesehatan di SMP se-Kecamatan Matesih Kabupaten Karanganyar, meliputi:

1. Faktor kemampuan menganalisa masalah dalam proses pembelajaran Pendidikan Jasmani, Olahraga dan Kesehatan.

Faktor ini dapat diartikan sebagai kepekaan guru dalam menganalisa permasalahanpermasalahan yang muncul dalam proses pembelajaran Pendidikan Jasmani, Olahraga dan Kesehatan Menganalisa masalah yang muncul dapat sebagai bahan evaluasi guru untuk mencoba meminimalkan agar masalah tersebut tidak muncul dalam kegiatan pembelajaran Penjasorkes selanjutnya. Menganalisa permasalahan- permasalahan yang muncul, berarti guru berpikir kreatif untuk mencari alternatif solusi pemecahan masalah tersebut.

2. Faktor kemampuan menciptakan ide-ide sebagai alternatif pemecahan masalah dalam proses pembelajaran Pendidikan Jasmani, Olahraga dan Kesehatan.

Masalah dalam proses pembelajaran Pendidikan Jasmani, Olahraga dan Kesehatan sangat kompleks, salah satunya adalah minimnya ketersediaan sarana prasarana dan fasilitas pendukung pembelajaran. Mengatasi permasalahan tersebut seharusnya guru kreatif dengan menciptakan ide-ide dalam memodifikasi membuat alat pendukung pembelajaran Penjasorkes dengan memanfaatkan media barang bakas. Contoh tidak adanya alat cakram di sekolah dapat dengan menggunakan piring plastik berisi pasir atau tidak adanya peluru guru menggunakan bola plastik dengan ukuran yang hampir sama dengan peluru berisikan pasir.

3. Faktor terbuka pada hal baru dalam proses pembelajaran Pendidikan Jasmani, Olahraga dan Kesehatan.

Keterbukaan guru akan hal-hal baru dalam proses pembelajaran Pendidikan Jasmani, Olahraga dan Kesehatan, dapat diartikan guru mau menerima saran dan juga mau ikut mempraktekkan semisal ada perkembangan metode pembelajaran yang baru.

Tingkat kreativitas guru untuk mengatasi keterbatasan sarana prasarana dalam proses pembelajaran Pendidikan Jasmani, Olahraga dan Kesehatan di SMP se-Kecamatan Matesih Kabupaten 
Karanganyar adalah berkategori "Rendah" dengan persentase sebesar 40\%. Hasil tersebut, tentu saja dipengaruhi oleh beberapa faktor, yaitu:

1. Kurangnya sarana dan prasarana dari masing-masing sekolah untuk pelaksanaan proses pembelajaran Pendidikan Jasmani, Olahraga dan Kesehatan. Seperti contohnya tidak adanya matras untuk praktek senam lantai dan tidak adanya lapangan untuk praktek atletik khususnya pada nomor lempar (lempar lembing, lempar cakram, dan tolak peluru).

2. Kurangnya kemampuan dari sebagian guru Pendidikan Jasmani, Olahraga dan Kesehatan di SMP se-Kecamatan Matesih untuk melihat masalah yang muncul/ terjadi dalam proses pembelajaran Pendidikan Jasmani, Olahraga dan Kesehatan di sekolah masing-masing.

3. Sebagian guru Pendidikan Jasmani, Olahraga dan Kesehatan di SMP se-Kecamatan Matesih belum mampu mengembangkan potensi yang ada pada diri pribadi masing-masing melalui bentuk kreativitas, dengan tujuan agar proses pembelajaran Penjasorkes dapat berjalan di sekolah.

4. Kemampuan dari sebagian guru Pendidikan Jasmani, Olahraga dan Kesehatan di SMP seKecamatan Matesih untuk menciptakan ide-ide sebagai alternatif pemecahan masalah dalam proses pembelajaran Pendidikan Jasmani, Olahraga dan Kesehatan di sekolah masing-masing.

5. Belum adanya keterbukaan dari sebagian guru Pendidikan Jasmani, Olahraga dan Kesehatan di SMP se-Kecamatan Matesih terhadap hal-hal baru dalam proses pembelajaran Pendidikan Jasmani, Olahraga dan Kesehatan.

\section{KESIMPULAN}

Berdasarkan hasil penelitian diatas menunjukkan bahwa besarnya tingkat kreativitas guru untuk mengatasi keterbatasan sarana prasarana dalam proses pembelajaran Pendidikan Jasmani, Olahraga dan Kesehatan di SMP se-Kecamatan Matesih Kabupaten Karanganyar, untuk kategori "sangat tinggi" sebanyak 2 guru Penjasorkes atau sebesar 20\%, kategori “tinggi” sebanyak 1 guru Penjasorkes atau sebesar 10\%, kategori "sedang" sebanyak 3 guru Penjasorkes atau sebesar $30 \%$, kategori "rendah" sebanyak 4 guru Penjasorkes atau sebesar 40\%, dan kategori "sangat rendah" sebanyak 0 guru Penjasorkes atau sebesar $0 \%$.

\section{IMPLIKASI}

Berdasarkan kesimpulan di atas, dari penelitian ini dapat ditemukan beberapa implikasi yaitu: 
1. Guru Pendidikan Jasmani, Olahraga dan Kesehatan di SMP se-Kecamatan Matesih Kabupaten Karanganyar, ada kemauan ke depan akan mampu secara menyeluruh mengembangkan potensi yang ada pada diri pribadi masing-masing melalui bentuk kreativitas, sehingga dapat sebagai salah satu pendukung agar tujuan dari proses pembelajaran Pendidikan Jasmani, Olahraga dan Kesehatan dapat maksimal berhasil di sekolah masing-masing.

2. Guru Pendidikan Jasmani, Olahraga dan Kesehatan di SMP se-Kecamatan Matesih Kabupaten Karanganyar akan lebih memahami dan mengerti tentang manfaat dalam hal dapat melihat masalah yang muncul/terjadi, menciptakan ide-ide sebagai alternatif pemecahan masalah, dan terbukanya terhadap hal-hal baru dalam proses pembelajaran Pendidikan Jasmani, Olahraga dan Kesehatan.

3. Menjadi masukkan bagi KKG Olahraga dalam data tentang besarnya tingkat kreativitas guru untuk mengatasi keterbatasan sarana prasarana dalam proses pembelajaran Pendidikan Jasmani, Olahraga dan Kesehatan di SMP se-Kecamatan Matesih Kabupaten Karanganyar,

\section{SARAN}

Berdasarkan kesimpulan penelitian di atas, saran yang dapat disampaikan yaitu:

1. Kepada para peneliti di bidang Pendidikan Jasmani, Olahraga dan Kesehatan yang akan melakukan penelitian dalam tema yang sama diharapkan agar menggunakan sampel yang lebih besar dengan variabel-variabelyanglain. Sehingga diharapkan hasil penelitian yang di dapat, akan lebih maksimal hasilnya

2. Kepada guru Pendidikan Jasmani, Olahraga dan Kesehatan di SMP se-Kecamatan Matesih, supaya mengadakan diskusi dan workshop yang berkaitan dengan tema kreativitas guru untuk mengatasi keterbatasan sarana dan prasarana dalam proses pembelajaran Pendidikan Jasmani, Olahraga dan Kesehatan serta dapat mengundang ahlinya.

3. Kepada SMP \& MTs se-Kecamatan Matesih sebaiknya mengusahakan terpenuhinya sarana dan prasarana untuk proses pembelajaran Pendidikan Jasmani, Olahraga, dan Kesehatan agar dapat berlangsung secara maksimal.

\section{DAFTAR PUSTAKA}

Annurahman. (2014). Belajar dan Pembelajaran. Bandung: Alfabeta.

Aziz, A.A. (2012). Guru Profesional dan Berkarakter. Klaten: Cempaka Putih. 
Bahagia,Y. Drs. (2000). Prinsip-Prinsip Pengembangan Dan Modifikasi Cabang Olahraga. Jurnal Pendidikan Olahraga dan Kesehatan. Vol. 03:03

Dermawan, D. (2013). Metode Penelitian Kuantitatif. Bandung: PT. Remaja Rosdakarya.

Fitrah. (2017). Belajar dan Pembelajaran. Jurnal Kajian Ilmu-ilmu Keislaman. Vol. 03: 337.

Herman, H \& Riyadi, A. (2018). SPORTIVE. Journal of Physical Education, Sport and Reaction. Vol. 1: 02 .

Ismail (2015). Peningkatan Kompetensi Pedagogik Guru PAI. Jurnal Mudarrisuna. Vol. 04: 707.

Kasim, M. (2011). Pentingnya Motivasi dan Minat Terhadap Manajemen Kinerja Guru dalam Pelaksanaan Pembelajaran Pendidikan Jasmani, Olahraga dan Kesehatan. Jurnal Academica Fisip Untad. Vol. 03: 662.

Komarudin. (2011). Peran Berpikir Kreatif dalam Proses Pembelajaran Matematika. Jurnal Formatif.

Vol. 2: 255.

Lestari, H. N., Margono, A., \& Shidiq, A. A. P.. Implementasi pembelajaran PJOK secara daring di SMP Negeri se-Kecamatan Patebon Kabupaten Kendal.. Jurnal PHEDHERAL.

Meka, D \& Tuansikal, A, R, S. (2015). Penerapan Modifikasi Pemnbelajaran Bola Basket Mini

Terhadap Motivasi Siswa dalam Pembelajaran Pendidikan Jasmani, Olahraga, dan Kesehatan.

Jurnal Pendidikan Olahraga dan Kesehatan. Vol. 03: 03.

Nana Syaodih Sukmadinana. (2017). Landasan Psikologi Proses Pendidikan. Bandung: Rosda Karya.

Ngalimun, Fadillah, H., \& Ariani A., (2013). Perkembangan dan Pengembangan Kreatifitas.

Banjarmasin: Aswaja Pressindo.

Norhasanah, (2004) "Karakteristik dan Unsur-Unsur Pembelajaran Kooperatif Tipe Artikulasi”.

Putro, B. N. (2015). Development of Instructional Media For Outside Shooting Basic Technique

Practice in Mini Basketball Club. WELCOME MESSAGE, 494.

Putro, W.E. (2012). Teknik Penyusunan Instrumen Penelitian. Yogyakarta: Pustaka Pelajar.

Risna. (2019). Profil Sarana Dan Prasarana Pendidikan Jasmani Olahraga Dan Kesehatan SMA Negeri

1 Bantaeng. Jurnal Fakultas Ilmu Keolahragaan.

Sugiyono. (2013). Metode Penelitian Kombinasi (Mixed Methods).Bandung:Alfabeta.

Wiarto,Giri. (2015). Inovasi Pembelajaran dalam Pendidikan Jasmani. Yogyakarta: Laksitas.

Yulianto, A., Kaswari, Supriatna, E. (2015). Persepsi Siswa Terhadap Penjasorkes di SMK dan SMA se- Kecamatan Mempawah Timur Kabupaten Pontianak. Jurnal Program Studi Pendidikan Jasmani Kesehatan dan Rekreasi FKIP UNTAN. 